\title{
Crónica del seminario de Buenos Aires La migración internacional en América Latina en el nuevo milenio
}

\section{ISA RG 31}

\author{
Graciela Sarrible \\ Universitat de Barcelona \\ Departament de Teoria Sociològica i Metodologia de les Ciències Socials \\ Avda. Diagonal, 690. 08034 Barcelona
}

El Comité de Investigaciones en Sociología de las Migraciones de la ISA organizó en Buenos Aires, entre el 2 y el 4 de noviembre de 2000, un seminario sobre migración internacional en Latinoamérica. Colaboraron apoyando al seminario, no sólo los organismos locales, como el Gobierno de la Ciudad, sino también el CELADE, organismo que depende de la ONU y que tiene su sede en Chile, CLACSO (organismo latinoamericano de ciencias sociales) y una serie de institutos universitarios y académicos argentinos.

Estuvo presidido por el coordinador general del comité local, Dr. Enrique Oteiza, y secundado por una serie de organismos específicos que se dedican a la investigación en migraciones. Entre ellos cabe nombrar al CEMLA, que edita una revista de migraciones, el CENEP (de población), la AEPA (también de población) o el Instituto Gino Germani de la Facultad de Ciencias Sociales de la Universidad de Buenos Aires.

Lo más interesante de estas reuniones son, a mi entender, los trabajos originales que se presentan y las discusiones que generan. En este sentido fue un seminario muy animado. Entre las personas asistentes no sólo había participantes y ponentes, sino también otros investigadores que no presentaban sus trabajos pero que deseaban escuchar y discutir los que se exponían en el seminario.

Por razones de organización, después del primer día se reunieron las ponencias para no tener sesiones a la misma hora, lo que permitió evitar elecciones que nos dejan sin conocer una parte de los trabajos que se exponen. Se presentarán, a continuación, algunos de ellos, para dar una idea del panorama general de la investigación sobre las migraciones en América Latina y de las aportaciones específicas que tuvieron lugar en el seminario.

La primera sesión temática se dedicó a las políticas migratorias y a los derechos humanos, lo que señala el marco institucional y normativo como el inicio del análisis de la cuestión. Muy interesante fue el resumen de las políticas migratorias en la Argentina, presentado por Susana Novick y Enrique Oteiza, del Instituto de Investigaciones Gino Germani, de la Universidad de Buenos Aires, en el cual se destacaba la pervivencia de ciertas leyes de la dictadura, no derogadas durante algún tiempo. Por otra parte, la amnistía migratoria parece 
contrastar con un discurso oficial considerado discriminatorio, como culminación de una etapa marcada por una serie de contradicciones y por profundos cambios institucionales.

El trabajo de Leticia Calderón Chelius, del Instituto Mora de México, trató la extensión del voto a los emigrantes del exterior como un proceso de reconocimiento de esos derechos. Mientras que varios países aprobaron esta medida, pocos la han llevado a cabo. El voto, más que un derecho, todavía puede ser una reivindicación de aquéllos que viven fuera, no pueden votar en sus sociedades de residencia y tampoco lo hacen en las de origen.

El tercer trabajo de la mesa trataba la cuestión de los argentinos en España y dividía al período estudiado, que se iniciaba en 1976, en dos momentos bien distintos, no sólo por las motivaciones de quienes marchaban, por la cantidad de personas que partían, sino también por la situación de las sociedades receptoras, en Europa, que no eran las mismas antes y después de 1983. Lo más importante era destacar que también los españoles migraban en ese mismo período y que los regresos desde Argentina podían ser numéricamente más importantes que los efectivos de argentinos registrados en España.

La aportación de Alicia Maguid, del INDEC, destaca las magnitudes de los movimientos en Centroamérica y la dirección, tanto intrarregional como hacia Estados Unidos, de estas migraciones. Por una parte, Costa Rica sigue siendo un foco de atracción importante para los países del entorno. Por otra, Estados Unidos sigue recibiendo a las personas de la región. Destacó, a través de estadísticas precisas, lo que significa la ayuda desde el exterior (remesas) para las familias, para las de recursos limitados en particular y para las de las zonas rurales, permitiendo comprender mejor las razones de la partida.

El trabajo de Diego Casaravilla provocó una cierta polémica al tratar la espinosa cuestión de los migrantes en situación irregular y el incremento de los prejuicios hacia las personas provenientes de los países limítrofes. Al exponer el tratamiento de la prensa a la cuestión, la discusión se centró en las imágenes que se querían transmitir más que en la realidad de esos mismos migrantes.

La ponencia de María Luján Leiva, sobre la emigración de profesionales y las políticas de vinculación en la Argentina, despertó el interés al tratarse de un grupo específico, siempre estudiado aparte y pocas veces considerado en los grandes flujos de migrantes. Los profesionales que habían partido de Argentina tuvieron oportunidades de retornar, en algunos casos y hace muchas décadas, al crease grupos de investigación ad-hoc, para que estas personas tuvieran las mismas condiciones que en las sociedades donde estaban residiendo y decidieran volver. Sin embargo, las políticas actuales intentan vincular al experto que reside en el exterior con el país de origen pero no hacerlo retornar. Una de las razones que apuntó para evitar ese retorno residiría en las reticencias que provoca en el medio académico el regreso de ciertas personas, con prestigio internacional y que podrían competir por puestos mejor retribuidos.

Lydio Tomasi, secretario del Grupo de Investigación de la ISA y presidente del Centro de Nueva York, trazó un panorama general de las migraciones entre los dos subcontinentes o entre las dos zonas, norte y sur, de América. 
Resulta evidente que para los Estados Unidos es crucial el peso de los migrantes mexicanos, no sólo en el panorama general de los extranjeros que entran y residen, sino también en el marco de todas las migraciones latinoamericanas. Aunque se ubican en pocos estados en el sur, esta comunidad centra la mayoría de las investigaciones que se refieren a las personas de habla española. Una aparente contradicción residiría en el hecho de que la importancia de las migraciones en el continente crece, frente al hecho de que las políticas específicas no se han definido claramente o no han avanzado con la misma rapidez que los últimos flujos.

Tanto el representante del Instituto que realiza los censos en Argentina, Alejando Giusti, como el del CELADE, Martínez Pizarro, o la profesora Adela Pellegrino, de la Universidad de la República de Uruguay, han trabajado sobre los datos censales, sobre todo de 1970 y 1980 . Existe un banco de datos, disponibles para los investigadores, que lo han aprovechado y han realizado numerosos trabajos. Estos datos permiten observar las situaciones a través de los recuentos censales. A pesar de que parezca que las fechas no son tan próximas, representa un esfuerzo no sólo interesante sino también valioso para poder analizar la situación previa a la inmediata y medir qué ha sucedido en ese tiempo anterior. Se está preparando el censo próximo y las encuestas de migraciones se están afinando, de acuerdo con las demandas de los usuarios de esos datos, introduciendo las variables más solicitadas.

El panorama general de las migraciones internacionales en un amplio período, que trazó la profesora A. Pellegrino en su exposición, fue elocuente del cambio del fin de siglo y de las tendencias de lo que puede ser el futuro. Expuso con claridad la transformación del continente de ser una región de inmigración a serlo de emigración, de recibir a intercambiar en la misma región, pero también de expulsar hacia el norte del continente y en menor medida hacia otras zonas. Los indicadores sociales marcaron la diferencia de la tipología de países que expuso, ente los que tienen tantos profesionales como los que emigran o los que tienen una sangría de profesionales, porque se van en gran medida, frente a una proporción menor que permanece.

Otras ponencias que puede ser interesante exponer en este resumen, son las que se refieren a las estrategias de inserción de los caboverdianos, a las redes de ayuda mutua de los bolivianos y la diáspora de los vascos. Los temas sociológicos son los que primaron en esta reunión, ya que se trata de un grupo de la ISA, frente a las estimaciones cuantitativas o a meras cuestiones económicas, que no representaron centros de interés, ni en las exposiciones, ni en las discusiones que las siguieron.

Evidentemente, la cuestión de los caboverdianos no es cuantitativa, ya que siempre han constituido un grupo reducido, pero sí lo es desde el punto de vista del cambio en sus modos de inserción. Los habitantes de estas islas de África fueron primero a los Estados Unidos y después de las restricciones de los años veinte, se dirigieron hacia Argentina, entre otros destinos. Estas migraciones se interrumpieron alrededor de los sesenta, cuando comenzaron a dirigirse primordialmente a destinos europeos. 
En primer lugar, la nacionalidad de estos migrantes era portuguesa hasta la independencia, por lo que, debido a la antigüedad de la migración, la inscripción en el Consulado en Buenos Aires ha tenido que ser un acto voluntario, de reafirmación de la identidad, que no todos los que tenían ese origen, han acometido. Hubo una época en que la comunidad tendía a diluirse y negar su identidad. Marta Maffia mencionó la cuestión de la invisibilidad que ya ha aparecido en otros trabajos, refiriéndose a la necesidad de los miembros de no aparecer como comunidad, de cambiar y parecerse a los otros. Puede sorprender, pero también se valora como una estrategia en el sentido apuntado, que alrededor del $90 \%$ de la comunidad tuviera casamientos exogámicos, en especial con españoles e italianos.

En este caso, señalaría algo que no apuntó la autora. No sólo estas dos comunidades europeas eran las más numerosas en la Argentina, sino también las más permeables. $\mathrm{Al}$ ser tan numerosas, los casamientos endogámicos hubieran sido muy fáciles de llevar a cabo, dado el número elevado entre los que se podía realizar la elección, pero no lo fue, demostrando que el hecho de ser numéricamente importantes no los hizo desdeñar a otras comunidades menores en número, con las que se mezclaron.

Razones de estas estrategias que podría conducirlos a la desaparición como grupo de los caboverdianos, eran las condiciones traumáticas de la partida, provocadas por hambrunas y falta de medios o la negritud en una sociedad de tinte claro o el mismo ascenso social de algunos miembros, que los llevaba a evitar a otros de la comunidad. Ahora que la migración es antigua y que no se plantean problemas de ninguna clase, los jóvenes comienzan a rescatar sus bailes, su gastronomía y las manifestaciones culturales que los pueden llevar a una identificación como comunidad, frente a la estrategia contraria de la generación precedente.

El trabajo sobre las redes de ayuda mutua de los bolivianos, presentado por Eduardo Bologna, destacaba algunos aspectos comunes a muchas migraciones. En primer lugar, el hecho de que las personas llegaban teniendo, en la mayoría de los casos, un familiar que los esperaba, los alojaba y les ayudaba a buscar trabajo. Esto era cierto salvo para los estudiantes, que venían por otras razones. En segundo lugar, que el funcionamiento de las redes sigue explicando socialmente la alimentación de flujos y destinos precisos, más allá de la cercanía de las zonas. Los inmigrantes estudiados en la segunda encuesta se encontraban en la Patagonia, en la provincia de Neuquén, en el límite con Chile, muy lejos de la zona limítrofe con Bolivia. En tercer lugar y un hecho a contrastar con otras situaciones, no presentaban ni mayor tasa de actividad ni de desempleo que la población local. Las encuestas fueron realizadas en 1996 y 1999, la última.

La presentación de Ignacio Irazusta sobre la colectividad vasca de la ciudad de Buenos Aires fue sólo una parte del trabajo que lleva entre manos sobre este tema. Expuso la organización de esta colectividad en centros. Destaca el hecho de que más del $50 \%$ de las personas que participan en asociaciones en el extranjero se encuentran radicadas en ese país, según cifras del autor. Las 
formas en que se manifiesta la identidad de los inmigrantes de origen vasco provocó cierta polémica al destacar algunos aspectos como míticos o el hecho de reivindicar, como otros colectivos, que su dispersión por el mundo puede considerarse una diáspora, al igual que lo hacen otras comunidades que han tenido migraciones importantes en los siglos XIX y XX. Otras cuestiones fueron debatidas, pero, para ello, mejor sumergirse en el artículo y sacar sus propias conclusiones.

Las cuestiones sobre las identidades de las comunidades de inmigrantes en la Argentina es un foco de creciente interés para los investigadores. No sólo para las nacionalidades históricas que se han consolidado en España y encuentran razones para recuperar a los familiares que han partido en momentos difíciles, sino también para otras comunidades, incluso minoritarias, como los caboverdianos, que están cambiando de actitud en las nuevas generaciones y tienen reivindicaciones precisas y distintas, frente a las necesidades de sus padres, cuando llegaron a una sociedad distinta.

Impresiones comunes del seminario de Buenos Aires y de lo que está sucediendo en España hay muchas. Las situaciones, aunque parezcan lejanas, no sólo resultan comparables, sino que siempre se pueden aprovechar para establecer paralelos y contrastes. En primer lugar, las migraciones limítrofes son las que provocan rechazo, frente a las antiguas con origen en Europa. En segundo lugar, los conflictos, mediáticos o reales, que generan las personas que no tienen documentos para permanecer en el país, resultan similares, aunque no se resuelven de la misma manera. En tercer lugar, parecería que el llamado efecto llamada existiera. Esto significa que la televisión sigue mostrando lo bien que se vive en Europa, en general, y en España, en particular, y provocando el éxodo de jóvenes con estudios superiores desde la Argentina. De la misma manera, los familiares que envían dinero a otros países de América Latina, sobre todo Perú, renuevan la ilusión de que se gana más y de que se puede vivir mejor. Ésos son los grandes ejes, en términos sociales y en términos de destino, sobre los que giran los flujos de emigrantes.

A pesar de las distancias, las reacciones de xenofobia y racismo pueden darse en todas partes. En Argentina hubo campañas para que no se compraran productos extranjeros, en pro de la industria local y de los trabajadores locales, que se consideran fracasadas. La campaña de los periódicos, que muestran continuamente a las personas en situación irregular, provocan reacciones desmesuradas respecto a las verdaderas dimensiones de la migración.

En ningún caso debemos olvidar que los principales flujos migratorios son intrarregionales en estos momentos y que los primeros movimientos se producen en distancias no tan largas. Los bolivianos entran en la zona limítrofe del norte de Argentina, así como los paraguayos. Pero después de un tiempo se desplazan dentro del territorio hasta los lugares más alejados.

La idea de un nuevo Schenguen en el cono sur, como solución a los problemas de las personas extranjeras sin documentos, por suerte, fue rechazada por el Dr. Oteiza, que apeló no a una libertad restringida de trabajadores de una lista reducida de nacionalidades, sino al reconocimiento de derechos universales 
que no dejen fuera a ningún trabajador por motivos de la nacionalidad que ostente. Lamentablemente, los pactos regionales refuerzan los sentimientos de derechos recíprocos, limitados sólo a los países firmantes, sin reconocer los mismos derechos a otros países, sólo porque no integran un pacto económico regional, del que quizás han quedado excluidos desde el inicio.

Otra de las percepciones erróneas, que podrían compartir varios países de inmigración en la actualidad, la constituye la imagen de un incremento. Esa idea de que llegan muchos puede ser falsa. El Dr. Oteiza recalcó que las personas están «ilegalizadas por el sistema»; o sea que es el marco institucional el que define quién está dentro y fuera de la legalidad. El director del CENEP, Dr. Alfredo Lattes, también destacó la idea de la heterogeneidad y de la riqueza en el estudio. No reducirse a ciertos grupos o tender a generalizar cuestiones, sino mostrar la diversidad que implica la migración, para no cernirla a un solo modelo o a una sola situación.

Más allá de las polémicas, de lo que se aprende asistiendo a eventos donde los intercambios son tan fluidos y los trabajos tan variados, siempre queda la posibilidad de consultar los trabajos y leerlos a través de la red. 